\title{
Harran Ören Yeri Kazısında Bulunan Kabartma Yazıların Üç Boyutlu Olarak Modellenmesi
}

\author{
Nizar POLAT ${ }^{1}$, Mehmet ÖNAL $^{2}$, Yunus KAYA ${ }^{1 *}$, Abdulkadir MEMDUHOĞLU $^{1}$, \\ Neslihan KAYA ${ }^{3}$, Mustafa ULUKAVAK ${ }^{1}$, Süheyla İrem MUTLU², Semih MUTLU² \\ ${ }^{1}$ Harran Üniversitesi, Mühendislik Fakültesi, Harita Mühendisliği Bölümü, Şanlıurfa \\ ${ }^{2}$ Harran Üniversitesi, Fen Edebiyat Fakültesi, Arkeoloji Bölümü, Şanlıurfa \\ ${ }^{3}$ Sorbonne University, Department of Archaeology, Paris, France \\ (ORCID: 0000-0002-6061-7796) (ORCID: 0000-0002-5182-4443) (ORCID: 0000-0003-2319-4998) \\ (ORCID: 0000-0002-9072-869X) (ORCID: 0000-0001-8401-6306) (ORCID: 0000-0003-2092-3075)
}

(ORCID: 0000-0001-7935-2890) (ORCID: 0000-0003-2920-6275)

\begin{abstract}
Öz
Kültürel miras olarak da nitelendirilen arkeolojik eserlerin korunması ve kayıt altına alınarak gelecek nesillere ulaştırılması insanlığın ortak görevi olarak kabul edilebilir. Kültürel mirasın belgelenmesinde öncelikle tarihi eserlerin mevcut durumu belirlenmelidir. Bunun için literatürde çeşitli teknikler kullanılmaktadır. Bu bağlamda, son zamanlarda teknolojik gelişmelere paralel olarak kültürel mirasın dokümantasyonu çalışmalarında fotogrametri tekniği yoğun olarak kullanılmaya başlanmıştır. Çoğunlukla harita ve sayısal yükseklik modeli gibi topografik ürünlerin elde edilmesi amacıyla kullanılan fotogrametri, iki boyutlu fotoğraflardan üç boyutlu bilgi sağlamasından dolayı farklı disiplinlere de katkıda bulunmaktadır. Bu sebeple arkeolojik eserlerin sayısal olarak dokümantasyonu çalışmalarda ciddi avantajlar sağlamaktadır. Bu çalışmada, Harran Ören Yeri kazı alanında bulunan tahrip olmuş bazı kabartma yazı örnekleri yersel fotogrametri ve hareketten Hareket Tabanlı Yapısal Algılama (SfM) yöntemiyle üç boyutlu olarak modellenmiştir. Çalışma sonunda yazılar için sayısal yüzey modeli oluşturulmuş ve bazı harf ve rakamlar kayıt altına alınmıştır. Yazıtlarda deformasyon ve eksiklikler bulunduğu için anlamlı bir kelime çıkarılmamıştır. Ancak çalışmanın sonuçları yersel fotogrametri ve SfM yönteminin avantajlarını barındırmaktadır. Arkeolojik alanlarda elde edilen benzersiz yapıtların fotogrametrik yöntemle ölçekli bir şekilde kayıt altına alınması önemlidir.
\end{abstract}

Anahtar kelimeler: Arkeoloji, Fotogrametri, 3B Model, Harran, Kitabe.

\section{Three-Dimensional Modeling of Relief Scriptures Found in Harran Ruins Excavation}

\begin{abstract}
It can be accepted as the common duty of humanity to protect archaeological artifacts as a part of cultural heritage and to deliver them to future generations by documenting them. In order to document cultural heritage, primarily the current status of historical artifacts should be determined. Various techniques are used in the literature for this. In this context, with the recent technological developments, photogrammetry technique has been used extensively in the documentation of cultural heritage. Photogrammetry, which is mostly used to obtain topographic products such as maps and digital elevation models, contributes to different disciplines as it provides three-dimensional information from two-dimensional photographs. Therefore, the digital documentation of archaeological artifacts provides serious advantages in studies. In this study, some of the relief scriptures found in the Harran Ruins excavation area were modeled as three dimensions by using terrestrial photogrammetry and the Structure from Motion (SfM) method. At the end of the study, a digital surface model was created for the scriptures and some letters and numbers were documented. Since there are deformations and deficiencies in the scriptures, no meaningful word has been derived. However, the results of the study have the advantages of the terrestrial photogrammetry and SfM method. It is important to documented the unique artifacts obtained in archaeological sites on a scale with the photogrammetric method.
\end{abstract}

Keywords: Archaeology, Photogrametry, 3D Model, Harran, Scripture.

*Sorumlu yazar: yunuskaya@harran.edu.tr

Geliş Tarihi: 17.02.2021, Kabul Tarihi: 01.04.2021 


\section{Giriş}

Tarihi eserler, yüzlerce yıllık bilgiye ev sahipliği yapan kültürel miraslardır ve bu bilgiler sonraki nesillere aktarılmalıdır. Bu tarihi miraslar, eski uygarlığın yaşam biçimini ve estetik anlayışını yansitırken; savaşlar, depremler gibi doğal ve yapay etkilerden dolayı zaman içinde değişime uğramışlardır. Tarihi eserin doğal dokularının zarar görmeden belgelenmesi ve korunması, gelecek nesillere aktarılması için vazgeçilmez bir unsurdur. Sadece ülkemizde değil, dünyanın birçok yerinde kültürel mirasların zarar gördügü bir gerçektir. Bu nedenle kültürel mirasın belgelenmesi çalışmaları tüm dünyada popüler konular arasındadır.

Tarihi alanların ve kültürel mirasların belgelenmesi, karmaşık ve çok yönlü bir süreçtir [1,2] Tarihi veya kültürel yapının dokümantasyonu, üç boyutlu (3B) uzayda yapının mevcut durumunu (şekil ve konum) belirlemek için gerekli olan etüt, süreç, depolama ve sunum adımlarının tamamını kapsar [3]. Kültürel mirasların belgelenmesi için birkaç teknik vardır [4,5]. Çok önemli ve gerekli olan bu tekniklerin başında fotogrametri [6-9] ve tarama yöntemleri [10] gelmektedir [4,11,12]. Bu noktada fotogrametrinin kısa sürede güvenilir bilgi sağlayabilmesi büyük bir avantajdır [13,14].

Günümüzde, fotogrametri ve bilgisayarlı görüş disiplinlerinin gelişmesiyle, görüntü tabanlı modelleme teknikleri lazer taramaya ciddi bir rakip haline gelmiştir [15]. Görüntü tabanlı modellemenin bazı dikkate değer avantajları şunlardır: düşük maliyetli ve renkli bilgiler içerir, kalibre edilmiş veya kalibre edilmemiş kameralar kabul edilebilir [16] ve lazer tarayıcıdan daha yoğun nokta bulutu oluşturabilir. Bu noktada klasik fotogrametriden farklı olarak hareket tabanlı yapısal algılama (Structure from Motion -SfM) yaklaşımı yaygın olarak kullanılmaktadır [8]. SfM, Fotogrametri ile aynı temel koşullar altında çalışır. İlgili nesnenin 3B yapısını elde etmek için üst üste binen görüntüler kullanılır. Agisoft Photoscan gibi birçok ticari yazılım da 3B modelleme için yaygın olarak kullanılmaktadır. Genel olarak fotoğrafları eşleme, seyrek ve yoğun nokta bulutu üretme, üç boyutlu model, sayısal yükseklik modeli ve ortofoto gibi birçok ürün üretmeye imkân vermektedir. Görüntü işleme adımları ciddi zaman alabilmektedir. Bu sebeple tam performanslı bir 3B model üretimi için yüksek performanslı bilgisayar kullanımı özellikle önerilmektedir [17]. Bu çalışmada tarihi Harran Ören Yeri arkeolojik alanında bulunan Arapça yazılı kitabelerden bazı örneklerin SfM metoduyla üç boyutlu modelleri sayısal olarak oluşturulmuş ve harfler belirlenmeye çalışılmıştır.

\section{Materyal ve Metot}

\section{1. Çalışma Alanı}

Çalışma, Şanlıurfa'nın Harran ilçesinde bulunan Harran Ören Yeri, İçkale'deki kazı alanında yapılmıştır (Şekil 1). İnsan uygarlığının çok eski yerleşim yerlerinden birisi olan Harran bölgesinin duvar yapıları ve altyapısı çok uzun bir süre içinde inşa edilmiş, onarılmış, büyütülmüş veya küçültülmüştür. Tarihi M.Ö. 5000 yılına kadar uzanan Eski Harran bölgesi Yukarı Mezopotamya'da yer alan önemli bir şehirdir. Bölgede farklı uygarlıklardan kalma pek çok sayıda tarihi eser bulunmaktadır. Bunlardan en önemlilerinden birisi de Harran kalesidir. Aktif kazı ve onarımın tamamlandığı kısımlar turistik amaçlı ziyarete açıktır. İlgili bölgeye ilişkin farklı zamanlarda arkeolojik çalışma yapılmıştır. Günümüzde Kültür ve Turizm Bakanlığ1, Türk Tarih Kurumu, Harran Üniversitesi ve yerel desteklerle Prof. Dr. Mehmet ÖNAL ve arkeoloji ekibi tarafından Harran Ören Yeri'nde arkeolojik kazı çalışmaları yürütmektedir. İçkale'de yapılan çalışmalarda Kale Hamamı [18,19], Güney-Doğu Kapısı ve dikdörtgen kulesi ile kalenin batısında 2. savunma sistemi meydana çıkarılmıştır. Kazı çalışmaları, kale köprüsü kalıntılarında devam etmektedir. Çalışmada, Harran İçkale'nin 2. katında, Hamam'dan merkezi yapıya geçilen holde (Yazıt 2 ve Yazıt 3) ve Güney Doğu Galeri'de (Yazıt 1) bulunan Arapça yazılı taşlar çalışılmıştır. Çalışmada kullanılan bu objelerden Yazıt 1 (HRK.15.12J-11f. Yüzey) koduyla, Yazıt 2 (HRK.20.12J-10e.404) koduyla ve Yazit 3 (HRK.20.12J-10e.401) koduyla Harran kazıları kapsamında adlandırılmıştır. 


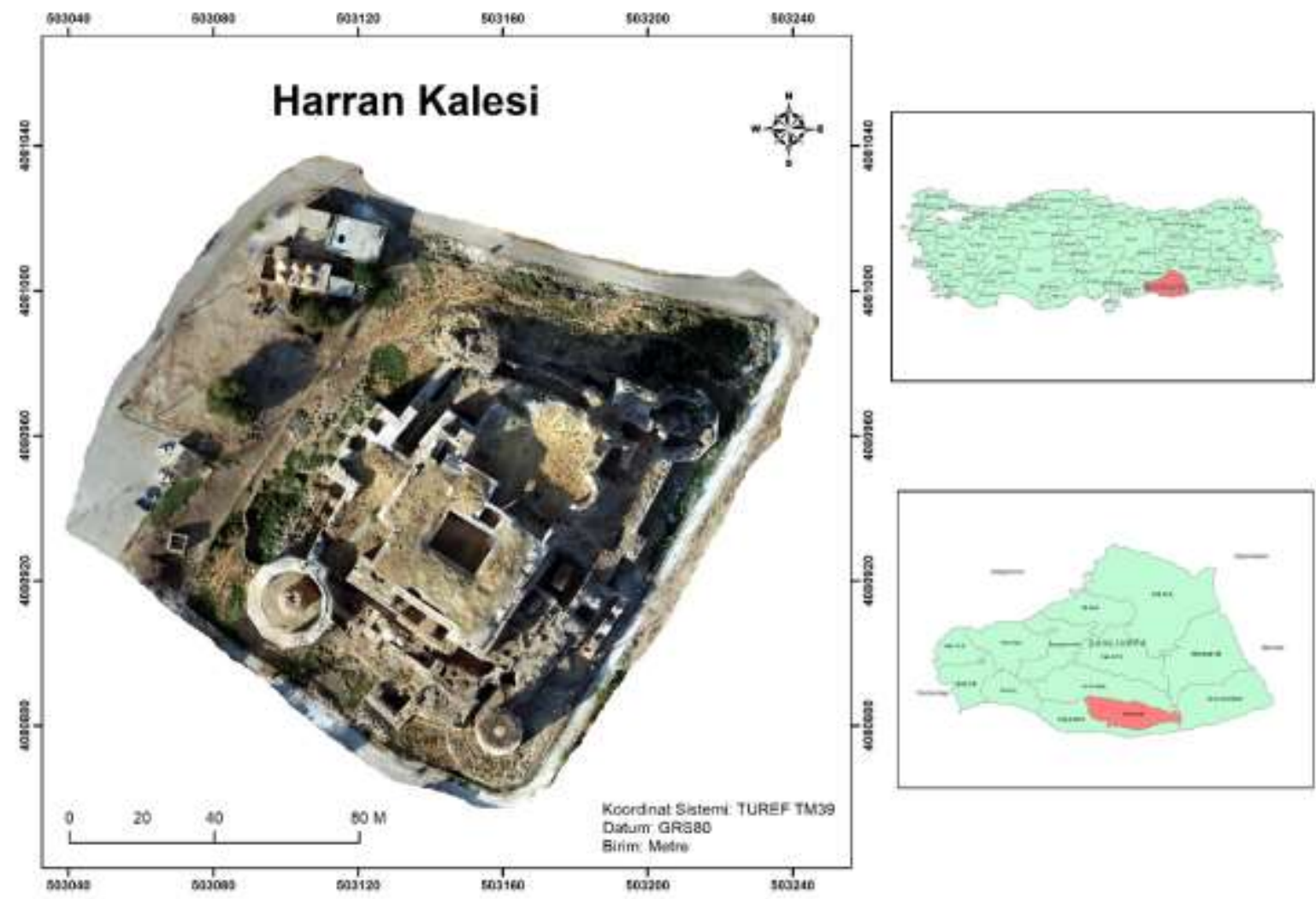

Şekil 1. Harran kalesi arkeolojik kazı alanı

\subsection{Ekipman}

Arkeolojik alandaki yazılı taşlar yersel fotogrametri tekniğiyle belgelenmiştir. Çalışmada belgeleme işleminin hassas bir şekilde yapılabilmesi için objenin tamamını kapsayacak şekilde bindirmeli fotoğraflar gerekmektedir. Çalışmada bu işlem için Canon EOS 2000D model DSLR fotoğraf makinesi kullanılmıştır (Şekil 2). Kullanılan sayısal fotoğraf makinesi ilişkin bilgiler Tablo 1'de verilmiştir.

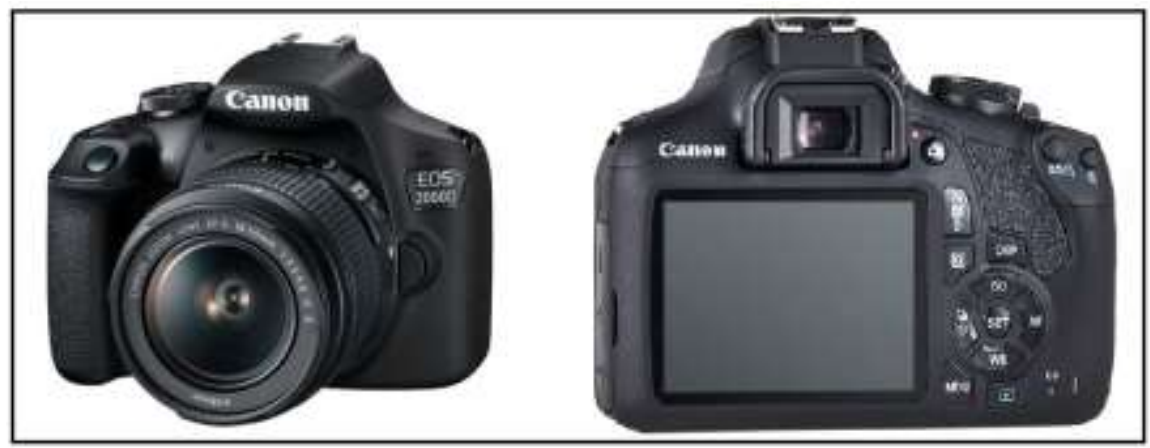

Şekil 2. Çalışmada kullanılan fotoğraf makinesi

Tablo 1. Kullanılan fotoğraf makinesinin teknik özellikleri

\begin{tabular}{|l|c|}
\hline \multicolumn{1}{|c|}{ Özellik } & Değer \\
\hline Mega piksel & 24.1 \\
\hline Maksimum Görüntü Çözünürlüğü & $6000 \times 4000$ \\
\hline Ağırlık & $475 \mathrm{~g}$ \\
\hline Boyut & $129 \times 101.3 \times 77.6 \mathrm{~mm}$ \\
\hline Sensör Boyutu & $22.3 \times 14.9 \mathrm{~mm}$ \\
\hline
\end{tabular}




\subsection{Yöntem}

Çalışmada yerden çekilen fotoğraflarla üç farklı modele ait yoğun nokta bulutu ve 3B model üretilmiştir. İnsan boyundan daha büyük olmayan yapılar için kullanışlı bir yöntem olan yersel fotogrametri basit sayısal el kameralarıyla çekilen fotoğrafları yüksek hassasiyetli 3B modele dönüştürebilmektedir. Çalışmaya konu olan kabartma yazıları dünyada çok yoğun olarak kullanılan SfM metoduyla 3B olarak modellenmiştir. SfM yaklaşımı bilgisayarla görme topluluğu tarafindan otomatik bir görüntü eşleme algoritması elde etmek için geliştirilmiş olsa da Stereoskopik Fotogrametri ile aynı temel koşullar altında çalışmaktadır [20-23]. Örtüşen görüntüler, ilgilenilen nesnenin 3B formunu elde etmek için kullanılır. Bununla birlikte, geleneksel Fotogrametri ile SfM arasında temel bir fark vardır. Geleneksel Fotogrametride, bir görüntüdeki noktaların 3B konumunu belirlemek için kameraların 3B konumu veya yer kontrol noktalarının (YKN) 3B konumu bilinmelidir. Bunun aksine, SfM, önceden tanımlanmış herhangi bir bilinen YKN seti olmadan geometrik parametreleri (yönelim, dahili ve harici parametreler) otomatik olarak belirler [24]. Bunun yerine, bu parametreler, aynı özelliklerin otomatik olarak eşleştirildiği yüksek düzeyde örtüşen bir görüntü seti kullanılarak eşzamanlı olarak çözülür [21]. Ardından, yinelemeli, doğrusal olmayan en küçük kareleri en aza indirme işlemi, eşleşen özellikleri görüntüden görüntüye izleyerek kamera konumlarını ve nesne koordinatlarını tahmin eder. Geleneksel fotogrametri ile karşılaştırıldığında, belirlenen kamera konumları görüntü uzayındadır, yani obje alanı göz önüne alındığında ölçek ve yönelim yoktur. Bu durum, harita üretimi gibi konularda az sayıda yer kontrol noktası kullanılarak 3 boyutlu benzerlik dönüşümü ile çözülmektedir [22]. Nesne modellenmesinde ise çoğu zaman ölçek belirlemek yeterli olmaktadır. Nesnenin kullanışlı bir 3B geometrisini elde etmek için, görüntülerin nesneyi tam olarak kaplaması gerekir. Bu şartın sağlanması için kameranın objeyi her açıdan görüntülemesinin gerçekleşmesi gereklidir. Çalışmada takip edilen adımlara ait iş akışı grafiği Şekil 3'de verilmiştir.

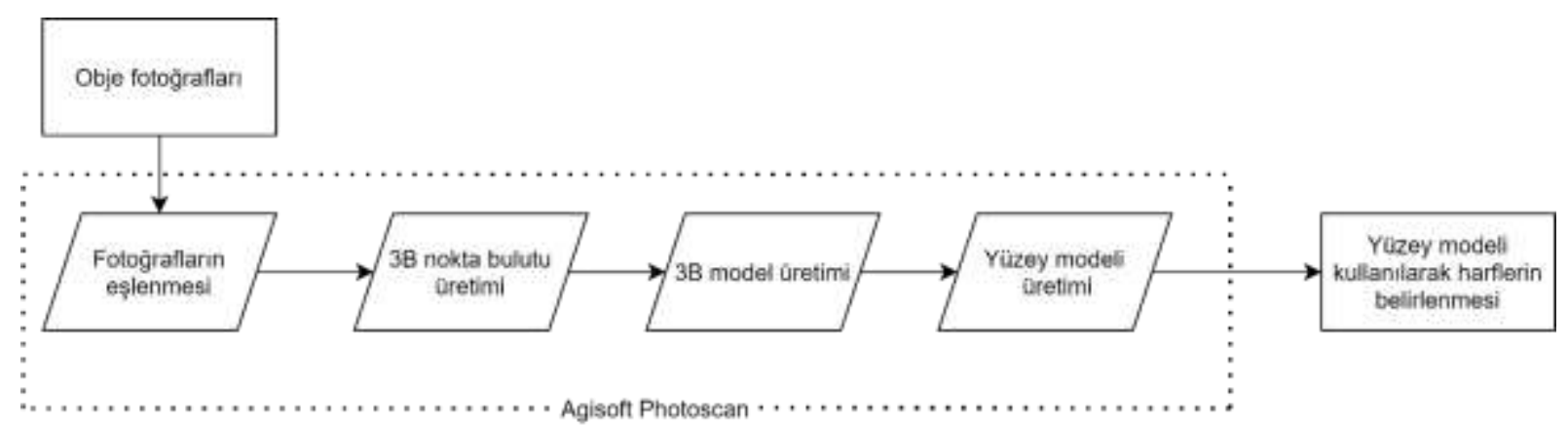

Şekil 3. İş akış grafiği

\section{Bulgular ve Tartışma}

Çalışmada tarihi Harran Ören Yeri arkeolojik kazı alanında tespit edilen üç farklı kesme taş üzerine kabartma yöntemiyle yazılmış Arapça yazıtlar ele alınmıştır. Kazı sonrası elde ettiğimiz kitabe parçaları zamanla kırılmış ve fiziksel değişime uğramıştır (Şekil 4). Geçirdiği fiziksel değişimler sonucu kitabelerin bazı kısımlarının okunması zorlaşmıştır. Kitabelerin sayısal olarak belgelenmesi için fotogrametri yöntemi ile 3B modelleme işlemi gerçekleştirilmiştir. Bu amaçla kazılar sırasında bulunan ve sınıflandırılmayı bekleyen üç farklı yazı parçası örnek olarak incelenmiştir (Şekil 4).

Üç yazı parçası için yersel olarak sırasıyla 35, 46 ve 29 fotoğraf çekilmiştir. Yazıları tam olarak modelleyebilmek için mümkün olduğunca objelerin her yönden fotoğrafları alınmıştır. Taşlar kale duvarı dibine sıralandığı için duvar tarafından istenildiği sayıda fotoğraf elde edilememiştir. Çekilen fotoğraflar iş akış grafiğginde verilen prosedür doğrultusunda işlenmiştir (Şekil 5). 


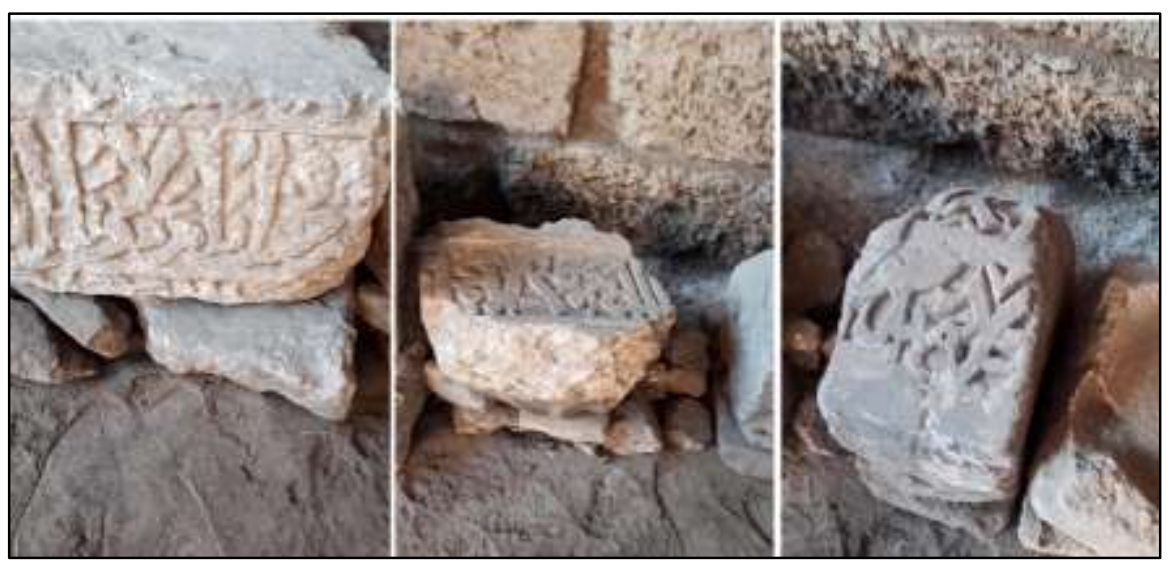

Şekil 4. Örnek yazı parçalarına ait fotoğraflar

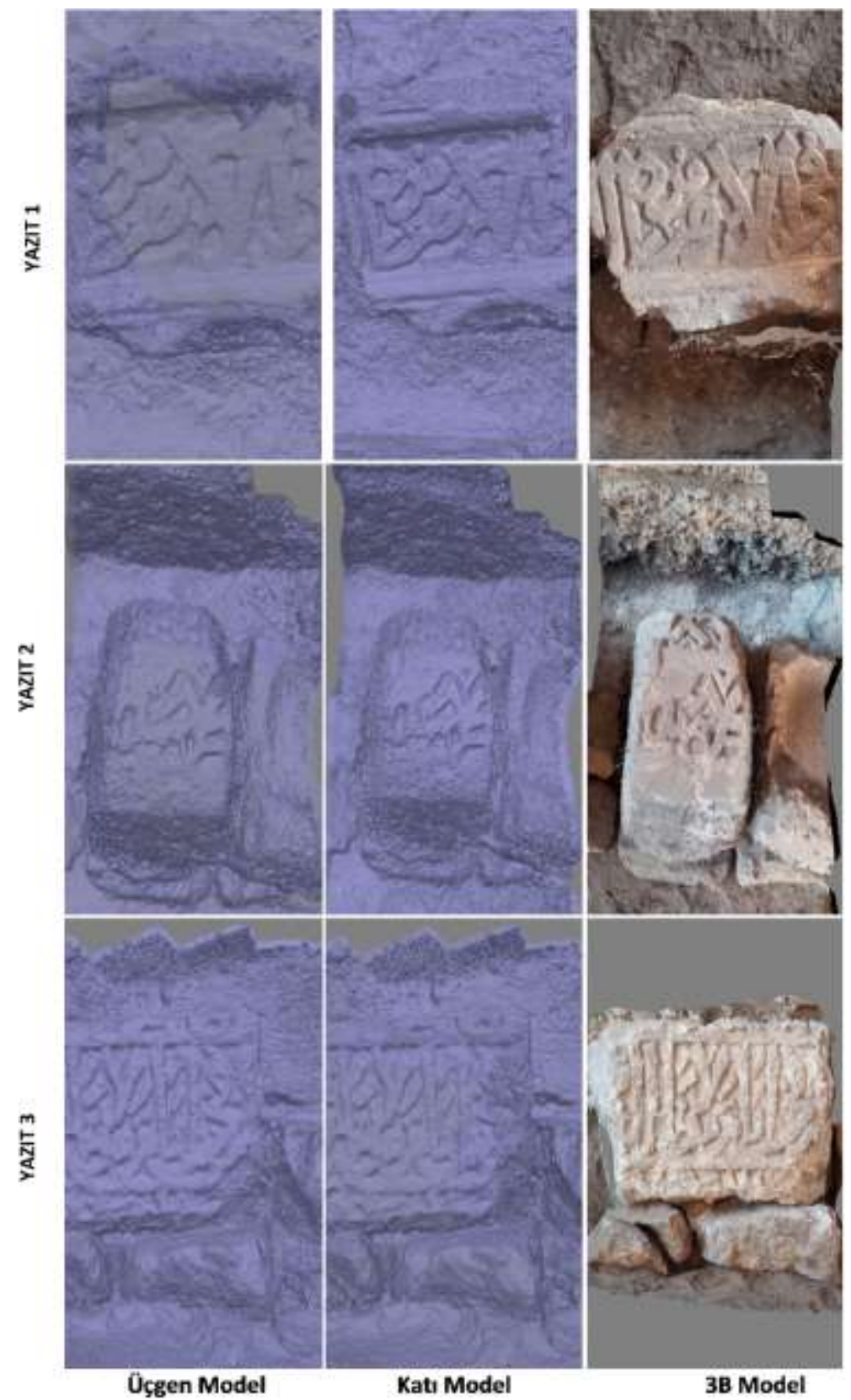

Şekil 5. Çalışma kapsamında yazılar için üretilen Üçgen, Katı ve 3B Model 
Üretilen modeller farklı yazılımlarda kullanılabilecek şekilde farklı dijital formatlara dönüştürülebilecek durumdadır. Üretilen modellere ait bazı bilgiler Tablo 2 de verilmiştir.

Tablo 2. Yazı parçalarına ait bilgiler

\begin{tabular}{cccc}
\hline & $\begin{array}{c}\text { Fotoğraf } \\
\text { Sayıs1 }\end{array}$ & $\begin{array}{c}\text { Yoğun Nokta } \\
\text { Bulutu }\end{array}$ & $\begin{array}{c}\text { 3B Model } \\
\text { Üçgen Sayıs1 }\end{array}$ \\
\hline $\begin{array}{c}\text { Yazıt 1 } \\
\text { (HRK.15.12J-11f. Yüzey) } \\
\text { Yazit 2 }\end{array}$ & 35 & 8297347 & 55315 \\
$\begin{array}{c}\text { (HRK.20.12J-10e.404) } \\
\text { Yazit 3 }\end{array}$ & 46 & 10829555 & 63912 \\
$($ HRK.20.12J-10e.401) & 29 & 5672835 & 40293 \\
\hline
\end{tabular}

Tablo 2'de de görüldüğü gibi çalışmada kullanılan taşlara ait nokta bulutları fotoğraf sayısıyla paraleldir. Fotoğraf sayısının en çok olduğu Yazıt 2'de en yoğun nokta bulutu üretilmiştir. Yazıt 3'te fotoğraf sayısı az olduğu için oluşturulan nokta bulutu da azdır. 3B model üçgen sayısı da nokta bulutu sayısına orantılı olarak artıp azalmaktadır. En düşük beş milyonun üzerinde 3B nokta üretilen yazılar, yüksek yoğunluk ile modellenmiştir. Üretilen nokta bulutlarından 3B modeller elde edilmiş ve bu modeller gerçek renk dokusuyla kaplanarak fotorealistik modeller elde edilmiştir. Modellerdeki harflerin daha net görselleştirmesi amacıyla modellerin sadece yazıların bulunduğu yüzeyi alınmış ve yüzeyin yükseklik modeli elde edilmiştir (Şekil 6). Üretilen yükseklik modeli sayesinde harflerin oluşturduğu kabartılar zeminden farklı bir şekilde renklendirildiği için harflerin okunabilirliği artırılmıştır.

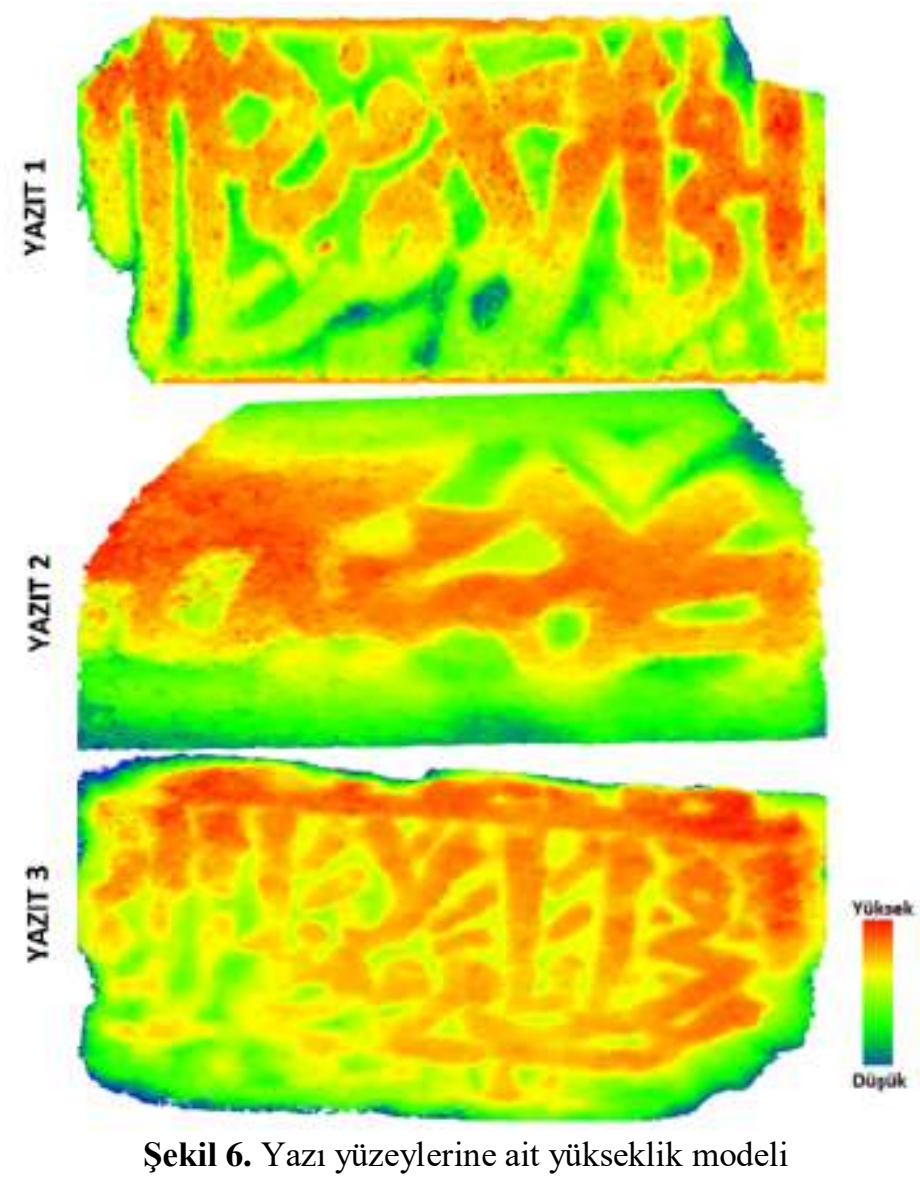

Bir anlamda harflerin taş üzerindeki kabartma haritası ya da derinlik haritası diyebileceğimiz bu model ile harflerdeki aşınma ve deformasyon daha net gözlenmiștir. Üretilen yüzey modellerinden, ciddi deformasyon olmasına rağmen uygulanan bu yöntem ile bazı Arapça harflerin okunmasını mümkün k1lmıştır (Tablo 2). 
Tablo 3. Yüzey modellerinden okunan bazı Arapça harfler

\begin{tabular}{|c|c|c|c|c|c|c|c|c|c|}
\hline Arapça Harf & 1 & ف & $y$ & ض ض & $\jmath$ & 5 & ن & $\dot{\tau}$ & J \\
\hline Türkçe Okunuş & Elif & $\mathrm{Fe}$ & Lamelif & Dat & $\mathrm{Ra}$ & Mim & Nun & H1 & Lam \\
\hline
\end{tabular}

Bazı Arapça harfler net okunurken bazı harfler okunamayacak durumda karşımıza çıkmaktadır. Harflerin okunmasını zorlaştıran en büyük etki kitabe yüzeyleri aşırı şekilde tahrip olmasıdır. Kitabe yüzeyindeki aşınma her harfte aynı şekilde görülmemektedir. Bu durum kitabede ortaya çıkan ve net bir şekilde anlaşılabilen harflerin birleştirmeyle bir sonuca varılabilmesini sağlamaktadır.

Yazılardan anlamlı kelime elde edilememiştir. Çünkü her bir modelin ait olduğu cümlede önceki ve sonraki kelimeler bilinmemektedir. Ayrıca önemli oranda deformasyon bulunmaktadır. Bu noktada en dezavantajlı durum yazıların kırılmış olmasından ziyade okunmalarını doğrudan etkileyecek olan erime ve aşınma durumudur. Bilindiği gibi kabartma taş yazılarında aşınma olması, ilgili harfin silinmesi demektir.

\section{Sonuç ve Öneriler}

Gelecek nesillere aktarılması gereken kültürel miraslarımızın korunması ve belgelenmesi bakımından çok önemlidir. Bu kapsamda, Harran arkeolojik kazı alanında bulunan Arapça sülüs yazılı taşlardan seçilen örnekler fotogrametrik yöntemle modellenmiştir. Gerçekleştirilen üç boyutlu modelleme ile elde edilen dijital kayıtlar, eserlerin sayısal olarak arşivlerin oluşturulmasına katkıda bulunmaktadır. Bunların yanı sıra elde edilen üç boyutlu modeller restorasyon ve restitüsyon çalışmalarında da kullanılabilecek niteliktedir. Elde edilen üç boyutlu model ve nokta bulutu gibi fotogrametrik ürünler farklı disiplinlerdeki çalışmaların ihtiyaçlarına da cevap verecek durumdadır. Çalışmada üç farklı taş yazı parçası seçilmiş ve fotoğrafları çekilerek fotogrametrik olarak işlenmiştir. Sonuçta üç boyutlu model ve yazı yüzeyine ait sayısal yüzey modeli elde edilmiştir. Sayısal yüzey modelinden okunabilen harfler okunarak kayıt altına alınmıştır. Aşınma, kııılma ve yosun gibi çevresel etmenlerden dolayı zarar gören yazı parçaları, çıplak gözle okunması ve algılanması zor bir durumdadır. Fotogrametrik yöntemle 3B olarak elde edilen modeller sayesinde alg1 ve okuma kolaylığ 1 elde edilmektedir. Bu noktada objelerin kale içerisinde kısmen loş bir ortamda olması ve aydınlatmanın yetersiz olması en büyük zorluktur. Bu sorun flaş kullanılarak aşılmıştır. Sonuç olarak fotogrametrik yaklaşım, dijital belgeleme ve üç boyutlu modelleme açışından ciddi katkılar sunmaktadır. Önümüzdeki çalışmalarda kazı bölgesindeki diğer yazıtların da üç boyutlu modellenmesi ve mümkün olurda sayısal ortamda uygun parçaların birleştirilmesi yönünde planlamalar yapılmaktadır.

\section{Yazarların Katkısı}

Yazarların makaleye olan katkıları eşit miktardadır.

\section{Çıkar Çatışması Beyanı}

Yazarlar arasında herhangi bir çıkar çatışması bulunmamaktadır.

\section{Araştırma ve Yayın Etiği Beyanı}

Yapılan çalışmada araştırma ve yayın etiğine uyulmuştur.

\section{Kaynaklar}

[1] Kulur S., Yilmazturk F. 2005. 3D Reconstruction of Small Historical Objects to Exhibit in Virtual Museum by Means of Digital Photogrammetry. CIPA XX. International Symposium, International Cooperation to Save the World`s Cultural Heritage, 26 Sep.-01 Oct., Torino, Italy.

[2] Ulvi A., Yakar M., Yiğit A.Y., Kaya Y. 2020. İHA ve Yersel Fotogrametrik Teknikler Kullanarak Aksaray Kızıl Kilise'nin 3 Boyutlu Nokta Bulutu ve Modelinin Üretilmesi. Geomatik Dergisi, 5 (1): 22-30. 
[3] Georgopoulos A., Ioannidis G. 2004. Photogrammetric and Surveying Methods for the Geometric Recording of Archaeological Monuments, Archaeological Surveys. FIG Working Week 2004, May 22- 27, 2004, Athens, Greece.

[4] Bohler W., Heinz G. 1999. Documentation, surveying, photogrammetry. XVII CIPA Symposium. Recife, Olinda.

[5] Şanlığlu I., Zeybek M., Karauğuz G. 2013. Photogrammetric Survey and 3D Modeling of Ivriz Rock Relief in Late Hittite Era. Mediterranean Archaeology and Archaeometry, 13 (2): 147-157.

[6] Kaya Y., Yiğit A.Y., Ulvi A., Yakar M. 2021. Arkeolojik Alanların Dokümantasyonununda Fotogrametrik Tekniklerinin Doğruluklarının Karşılaştırmalı Analizi: Konya Yunuslar Örneği. Harita Dergisi, 165: 57-72.

[7] Ulukavak M., Memduhoğlu A., Şenol H.İ., Polat N. 2019. Excavation Monitoring With UAV in Sanliurfa Castle Archaeological Site. Mersin Photogrammetry Journal, 1 (1): 23-26.

[8] Polat N., Önal M., Ernst F.B., Şenol H.İ., Memduhoğlu A., Mutlu S., Mutlu S.İ., Budan M.A., Turgut, M., Kara H. 2020. Harran Ören Yeri Arkeolojik Kazı Alanınındın Çıkarılan Bazı Küçük Arkeolojik Buluntuların Fotogrametrik Olarak 3B Modellenmesi. Türkiye Fotogrametri Dergisi, 2 (2): 55-59.

[9] Ulukavak M., Memduhoğlu A., Şenol H.İ., Polat N. 2019. The Use of UAV and Photogrammetry in Digital Documentation. Mersin Photogrammetry Journal, 1 (1): 17-22.

[10] Senol H.I., Erdogan S., Onal M., Ulukavak M., Memduhoglu A., Mutlu S., Ernst F.B., Yilmaz, M. 2017. 3D Modeling of A Bazaar in Ancient Harran City Using Laser Scanning Technique. International Archives of the Photogrammetry, Remote Sensing \& Spatial Information Sciences, 42.

[11] Scherer M. 2002. About the Synthesis of Different Methods in Surveying. XVIII International Symposium of CIPA, Potsdam, Germany.

[12] Şenol H.İ., Memduhoglu A., Ulukavak M. 2020. Multi Instrumental Documentation and 3D Modelling of an Archaeological Site: a Case Study in Kizilkoyun Necropolis Area. Dicle Üniversitesi Mühendislik Fakültesi Mühendislik Dergisi, 11 (3): 1241-1250.

[13] Yakar M., Yıldız F., Özkütük A., Neşeli O., Kurhan E., Durdu O. 2011. Sultanhanı Kervansarayı Fotogrametrik Rölöve Alımı ve 3 Boyutlu Modelleme Çalışması. 13. Türkiye Harita Bilimsel ve Teknik Kurultayi.

[14] Şasi A., Yakar M. 2018. Photogrammetric Modelling of Hasbey Dar'ülhuffaz (Masjid) Using an Unmanned Aerial Vehicle. International Journal of Engineering and Geosciences, 3 (1): 6-11.

[15] Remondino F., Barazzetti L., Nex F., Scaioni M., Sarazzi D. 2011. UAV Photogrammetry for Mapping and 3D Modeling Current Status and Future Perspectives. ISPRS ICWG I/V UAV-g Conference, Zurich, Switzerland.

[16] Colomina I., Blázquez M., Molina P., Parés M.E., Wis M. 2008. Towards a New Paradigm for High-Resolution Low-Cost Photogrammetry and Remote Sensing. IAPRS\&SIS, 1201-1206.

[17] Siebert S., Teizer J. 2014. Mobile 3D Mapping for Surveying Earthwork Projects Using an Unmanned Aerial Vehicle (UAV) System. Autom. Constr., 41: 1-14.

[18] Önal M. 2019. Harran 2017 Yılı Çalışmaları, 40. Kazı Sonuçları Toplantısı. 2. Cilt, Ankara, 632650.

[19] Önal M. 2020. Harran 2018 Yılı Çalışmaları, 41. Kazı Sonuçları Toplantısı 3. Cilt. Ankara, 157180.

[20] Tanskanen P., Kolev K., Meier L., Camposeco F., Saurer O., Pollefeys M. 2013. Live Metric 3D Reconstruction on Mobile Phones. in: 2013 IEEE Int. Conf. Comput. Vis., IEEE, 65-72.

[21] Snavely N.K. 2009. Scene Reconstruction and Visualization From Internet Photo Collections. Doctoral Thesis, University of Washington.

[22] Westoby M.J., Brasington J., Glasser N.F., Hambrey M.J., Reynolds J.M. 2012. Structure-fromMotion'photogrammetry: A Low-Cost, Effective Tool for Geoscience Applications. Geomorphology, 179: 300-314.

[23] Micheletti N., Chandler J.H., Lane S.N. 2015. Investigating the geomorphological potential of freely available and accessible structure-from-motion photogrammetry using a smartphone. Earth Surface Processes and Landforms, 40 (4): 473-486. 